\title{
Charging/Discharging of Au (Core)/Silica (Shell) Nanoparticles as Revealed by XPS
}

\author{
Ilknur Tunc, U. Korcan Demirok, and Sefik Suzer* \\ Chemistry Department and the Laboratory for Advanced Functional Materials, Bilkent University, \\ 06800 Ankara, Turkey
}

Miguel A. Correa-Duatre and Luis M. Liz-Marzan

Departmento de Quimica Fisica, Universidade de Vigo, 36310 Vigo, Spain

Received: October 2, 2005

\begin{abstract}
By recording XPS spectra while applying external voltage stress to the sample rod, we can control the extent of charging developed on core-shell-type gold nanoparticles deposited on a copper substrate, in both steadystate and time-resolved fashions. The charging manifests itself as a shift in the measured binding energy of the corresponding XPS peak. Whereas the bare gold nanoparticles exhibit no measurable binding energy shift in the $\mathrm{Au} 4 \mathrm{f}$ peaks, both the $\mathrm{Au} 4 \mathrm{f}$ and the Si 2p peaks exhibit significant and highly correlated (in time and magnitude) shifts in the case of gold (core)/silica (shell) nanoparticles. Using the shift in the Au $4 \mathrm{f}$ peaks, the capacitance of the 15-nm gold (core)/6-nm silica (shell) nanoparticle/nanocapacitor is estimated as $60 \mathrm{aF}$. It is further estimated that, in the fully charged situation, only 1 in 1000 silicon dioxide units in the shell carries a positive charge during our XPS analysis. Our simple method of controlling the charging, by application of an external voltage stress during XPS analysis, enables us to detect, locate, and quantify the charges developed on surface structures in a completely noncontact fashion.
\end{abstract}

\section{Introduction}

Preparation of nanoparticles with well-defined structures and tailored properties is of utmost importance for chemists and material scientists, as it is envisaged that they soon will revolutionize both our understanding and the production of advanced materials. ${ }^{1-11}$ Core-shell-type nanostructures are particularly important because they offer extra stability and multifunctionality. ${ }^{12-20}$ For the characterization of core-shelltype nanostructures, X-ray photoelectron spectroscopy, XPS, is vital because of the perfect match of its probe length $(\sim 10$ $\mathrm{nm}$ ) with the size of these particles. ${ }^{21}$ A number of articles have appeared dealing with the use of XPS for the characterization of various core-shell-type nanostructures, where the emphases have been on determinations of the chemical composition and structure. ${ }^{22-34}$ It is also possible to derive information related with dielectric properties of surface structures by recording their charging/discharging behavior, frequently encountered in XPS analysis of poorly conducting materials, as we showed by controlling this via application of an external voltage stress in either dc or pulsed modes..$^{35-38}$

The storage and manipulation of charges in a controlled manner represents an important fundamental scientific and technological challenge. Of the analytical methods for detecting charge storage, sensitive electroanalytical ${ }^{39,40}$ and scanning tunneling techniques ${ }^{41,42}$ lack the ability to determine the chemical identity, and optical techniques ${ }^{43-46}$ offer only limited capability. In contrast, XPS can provide information related to both chemical identity and dielectric properties, as was recently reported. ${ }^{38,41,42,47,48}$ In this contribution, we demonstrate that, by controlling the charging during XPS analysis, we can detect,

* Corresponding author. E-mail: suzer@fen.bilkent.edu.tr. locate, and quantify the charges developed on gold (core)/silica (shell) nanopraticles in both steady-state and time-resolved modes.

\section{Experimental Section}

Tetrachloroauric acid $\left(\mathrm{HAuCl}_{4} \cdot 3 \mathrm{H}_{2} \mathrm{O}\right)$, 3-aminopropyl trimethoxysilane (APS), and sodium silicate solution $\left[\mathrm{Na}_{2} \mathrm{O}\right.$ $\left(\mathrm{SiO}_{2}\right)_{3-5}, 27$ wt $\left.\% \mathrm{SiO}_{2}\right]$ were purchased from Aldrich. Bare $\mathrm{Au}$ nanoparticles were prepared using the method described earlier. ${ }^{13}$ Briefly, spherical gold nanoparticles with an average diameter of ca. $15 \mathrm{~nm}$ and a polydispersity of $10 \%$ were prepared by boiling $5 \times 10^{-4} \mathrm{M} \mathrm{HAuCl}_{4}$ in the presence of 1.6 $\times 10^{-3} \mathrm{M}$ sodium citrate for $15 \mathrm{~min}$. To prepare core-shell nanoparticles, after the above solution had been cooled to room temperature, APS $(5 \mu \mathrm{M})$ and sodium silicate solution $(0.01 \mathrm{wt}$ $\%)$ were added in turn, under vigorous magnetic stirring. The resulting dispersion $(\mathrm{pH} \approx 8.5)$ was allowed to stand for 3 days, resulting in the deposition of 5-7-nm-thick silica shells.

Both types of nanoparticles were deposited on copper tape and analyzed after being dried in air, using a Kratos ES300 electron spectrometer with $\mathrm{Mg} \mathrm{K} \alpha \mathrm{X}$-rays. UV-vis-NIR spectra and XRD patterns were recorded using a Cary 5E spectrometer and a Rikagu Miniflex diffractometer with $\mathrm{Cu}$ $\mathrm{X}$-rays, respectively. A dc voltage stress was applied to the sample rod (in good electrical connection with the copper tape) externally while spectra were recorded. For time-resolved measurements, the voltage was pulsed, and 200 spectra, each for 10-ms duration, were collected and stored separately. Details of our experimental setup and procedures for collecting data in both the dc and pulsed modes have been described in our earlier publications. ${ }^{37,38}$ 


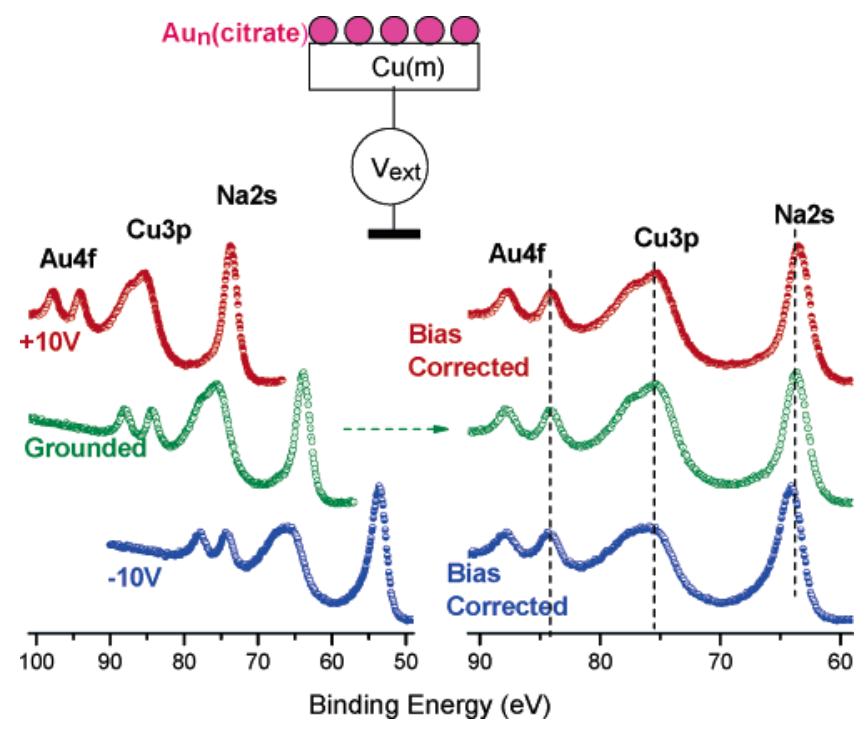

Figure 1. Part of the XPS spectra, corresponding to $\mathrm{Au} 4 \mathrm{f}, \mathrm{Cu} 3 \mathrm{p}$, and $\mathrm{Na} 2 \mathrm{~s}$ peaks, of bare gold nanparticles deposited on copper substrate, recorded when the sample was (i) grounded (middle), (ii) under $-10 \mathrm{~V} \mathrm{dc}$ bias (bottom), (iii) and under $+10 \mathrm{~V}$ dc bias (top). In the second half of the figure, the same spectra are displayed after being corrected for the bias shift. The inset shows schematically application of the external voltage stress to the sample (via the sample rod).

\section{Results and Discussion}

Figure 1 displays the region of the XPS spectra corresponding to $\mathrm{Au} 4 \mathrm{f}, \mathrm{Cu} 3 \mathrm{p}$, and $\mathrm{Na} 2 \mathrm{~s}$ peaks of only the bare gold nanoparticles on the copper substrate, recorded when the sample was (i) grounded, (ii) under $-10 \mathrm{~V}$ (dc) bias, and (iii) under $+10 \mathrm{~V}(\mathrm{dc})$ bias. For conducting samples such as copper tape, application of a negative bias shifts all of the peaks to higher kinetic energy (hence lower binding energy), and positive bias acts in the opposite direction, as shown in the figure. For nonconducting samples or regions of the sample with poor electrical conductivity, the shift is not symmetric, because, under a negative bias, the neutralization caused by low-energy electrons from a filament or stray electrons within the vacuum system is hindered..$^{35,36}$ This is exemplified by the $\mathrm{Na} 2 \mathrm{~s}$ peak, which charges and shifts differently from the others. The differential charging shifts of the $\mathrm{Na} 2 \mathrm{~s}$ peak with polarity become much clearer when the spectra are shifted back by exactly the same amount as the bias, as shown in the second half of the figure. The charging in the $\mathrm{Na} 2 \mathrm{~s}$ peak is not related to the main focus of this manuscript and therefore will not be discussed any further.

Figure 2 shows UV-vis-NIR spectra and the Si 2p, Au 4f, and $\mathrm{Cu} 2 \mathrm{p}$ regions of the XPS spectra (corrected for biasing) for both types of nanoparticles. The strong surface plasmon resonance band around $530 \mathrm{~nm}$ and the slightly broadened $(\Delta \Phi$ $>0.8^{\circ}$ ) XRD peak at $38^{\circ}$ (not shown) corresponding to $\mathrm{Au}(111)$ are indicative of the crystalline nature of the gold in both types of nanoparticles, and the presence of the additional Si $2 p$ peak, together with angle invariance of the $\mathrm{Au} 4 \mathrm{f} / \mathrm{Si} 2 \mathrm{p}$ peak intensity ratio, are direct verification of the core-shell structure in the latter case. ${ }^{34}$ The core-shell nanoparticles have, on average, a 15-nm-diameter gold core and a 6-nm shell as determined from their TEM images.

The most important feature in the XPS spectrum is related to the differential charging of the core-shell particles as evidenced with the shift in the measured binding energies with respect to the polarity of the external dc voltage stress. Whereas the $\mathrm{Au} 4 \mathrm{f}$ peaks are unshifted in the case of bare gold
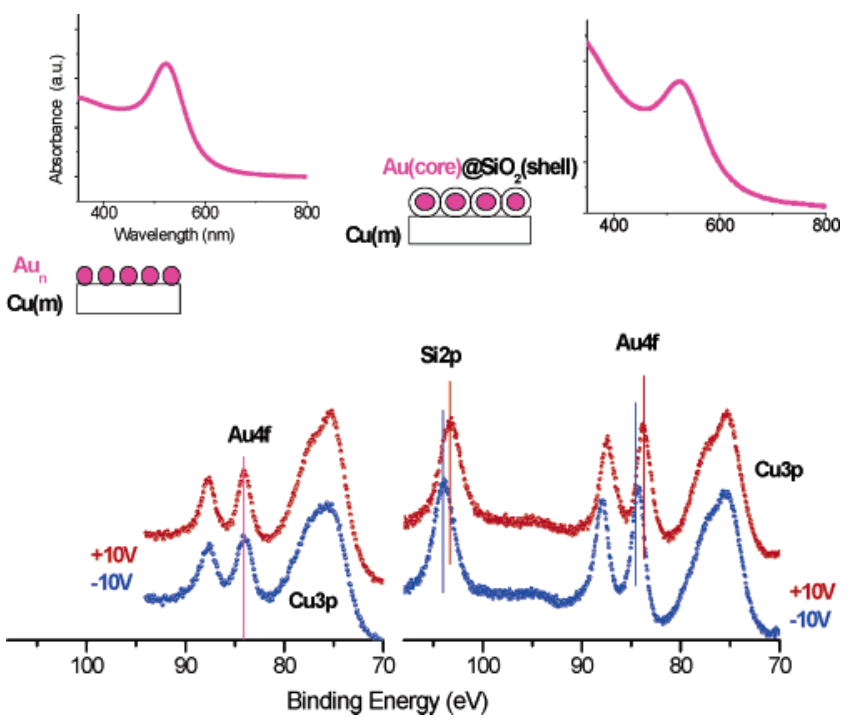

Figure 2. UV-vis spectra of bare gold and gold (core)/silica (shell) nanparticles and their corresponding XPS spectra of the Si 2p, Au 4f, and $\mathrm{Cu} 2 \mathrm{p}$ peaks, recorded while -10 and $+10 \mathrm{~V}$ dc voltage stresses were being applied.

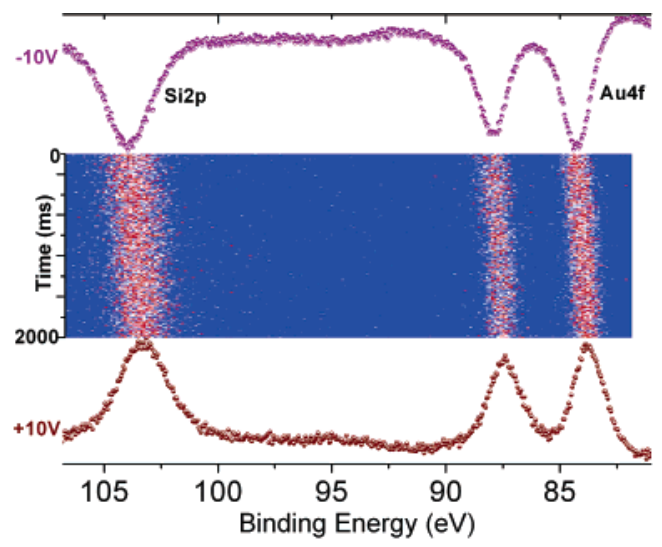

Figure 3. Two hundred XPS spectra, recorded with $10-\mathrm{ms}$ resolution, of the $\mathrm{Si} 2 \mathrm{p}-\mathrm{Au} 4 \mathrm{f}$ region of gold (core)/silica (shell) nanoparticles. At each step, the sample is first biased at $-10 \mathrm{~V}$, and a steep $+10 \mathrm{~V}$ pulse is applied, after which spectra are recorded and stored at 10-ms intervals for $2 \mathrm{~s}$.

nanoclusters, both the $\mathrm{Au} 4 \mathrm{f}$ and $\mathrm{Si} 2 \mathrm{p}$ peaks shift to higher binding energies for the core-shell nanoparticles, when recorded under $-10 \mathrm{~V}$ because of enhanced charging of the nanoparticles. Furthermore, their shifts are highly correlated in time, as shown in Figure 3, where 200 XPS spectra recorded with 10-ms time resolution are displayed. Note also that the $\mathrm{Cu} 2 \mathrm{p}$ peak does not shift at all. The shift is solely related to charge accumulation in the silica shell, the extent of which can be controlled by the magnitude and the polarity of the voltage stress, and the gold core experiences the same potential and shifts as the shell. We also examined Ag-coated silica nanoparticles under exactly the same conditions. In this case, the Si $2 p$ peak shifts in a similar fashion, but the $\mathrm{Ag} 3 \mathrm{~d}$ peaks exhibit no shift at all, because the silver atoms are now in the shell and in contact with the copper substrate.

The positive charges arise because of the core holes created by the very fast $\left(<10^{-12} \mathrm{~s}\right)$ photoelectron emission process and subsequent filling of these holes by outer electrons. The holes end up in the valence band and are stabilized in the large band gap of the silicon dioxide. Later, these holes are neutralized, on the time scale that we measure $(0.01-10 \mathrm{~s})$, by the lowenergy electrons falling on to the sample, the flux of which is 
controlled by the applied external voltage stress. Hence, we control and detect the charging and the discharging of these nanocapacitors.

The total charge stored in the silica shell of the nanocapacitor can be estimated from the measured $0.3 \mathrm{eV}$ difference in the $\mathrm{Au} 4 \mathrm{f}$ peak and the capacitance through the equation

$$
\Delta V=q e / C_{\mathrm{CS}}
$$

Using the expression of Oldfield, Ung, and Mulvaney ${ }^{45}$ for similar core-shell nanoparticles

$$
C_{\mathrm{CS}}=4 \pi \epsilon_{\text {Core }} \epsilon_{0} /\left[\left(1 / R_{\text {Core }}\right)-\left(1 / R_{\text {Shell }}\right)\right]
$$

and taking the dielectric constant of the silica shell as 3, we obtain a value of $60 \mathrm{aF}$ for the capacitance of the core-shell nanocapacitor. We can estimate that, on average, a maximum of 100 positive holes remain unneutralized on each particle while under $-10 \mathrm{~V}$ stress but become neutralized when $+10 \mathrm{~V}$ stress is applied externally. We can further estimate, by using the density of the bulk silica $\left(2.3 \mathrm{~g} / \mathrm{cm}^{3}\right)$ and the geometry of the core/shell nanoclusters, that, in the maximum charged case, 1 in 1000 silicon dioxide units carries a positive hole in these nancapacitors.

\section{Conclusions}

In short, we show that, by controlling the charging/discharging of gold (core)/silica (shell) nanoparticles during their analysis by XPS, we detect, in both steady-state and time-resolved fashions, the potential developed because of the positive charges on the core-shell nanoparticles/nanocapacitors. Our method is simple and provides a noncontact analytical detection system that also reveals the location and the chemical identity of the medium where the charges reside within the nanostructures.

Acknowledgment. This work was partially supported by TUBA (Turkish Academy of Sciences) and MEC (Ministerio de Educación y Ciencia, Spain).

\section{References and Notes}

(1) Henglein, A. Chem. Rev. 1989, 89, 1861.

(2) Stucky, G. D.; MacDougall, J. E. Science 1990, 247, 669.

(3) Alivisatos, A. P. Science 1996, 271, 2693.

(4) Grieve, K.; Mulvaney, P.; Grieser, F. Curr. Opin. Colloid Interface Sci. 2000, 5, 168 18.

(5) Shipway, A. N.; Katz, E.; Willner, I. Chem. Phys. Chem. 2000, 1,

(6) Lue, J. T. J. Phys. Chem. Solids 2001, 62, 1599.

(7) Tempelton, A. C.; Wuelfing, W. P.; Murray, R. W. Acc. Chem. Res. 2000, 33, 27. 3843 .

(8) Trindade, T.; O'Brien, P.; Pickett, N. L. Chem. Mater. 2001, 13,
(9) Brust, M.; Kiely, C. J. Colloids Surf. A 2002, 202, 175.

(10) Kamat, P. V. J. Phys. Chem. B 2002, 106, 7729.

(11) El-Sayed, M. A. Acc. Chem. Res. 2004, 37, 326.

(12) Chen M. S.; Goodman, D. W. Science 2004, 306, 252.

(13) Liz-Marzán, L. M.; Giersig, M.; Mulvaney, P. Langmuir 1996, 12, 4329.

(14) Liz-Marzán, L. M.; Mulvaney, P. J. Phys. Chem. B 2003, 107, 7312.

(15) Hardikar, V. V.; Matijevic, E. J. J. Colloid Interface Sci. 2000, $221,133$.

(16) Hodak, J. H.; Henglein, A.; Hartland, G. V. J. Chem. Phys. 2001, $114,2760$.

(17) Caruso, F. Adv. Mater. 2001, 13, 11.

(18) Schierhorn, M.; Liz-Marzan, L. Nano Lett. 2002, 2, 13.

(19) Liu, Y.; Yin, Y.; Xia, Y. Nano Lett. 2002, 2, 785.

(20) Salgueirino-Maceira, V.; Caruso, F.; Liz-Marzan, L. J. Phys. Chem. 2003, 107, 10990.

(21) Briggs, D.; Seah, M. P. Practical Surface Analysis, 2nd ed.; Wiley: Chichester, U.K., 1999; Vol. I.

(22) Werthein, G. K.; DiCenzo, S. B. Phys. Rev. B 1988, 37, 844.

(23) Hoener, C. F.; Allan, K. A.; Bard, A. J.; Campion, A.; Fox, M. A.; Mallouk, T. E.; Webber, S. E.; White, J. M. J. Phys. Chem. 1992, 96, 3812.

(24) Katari, J. E. B.; Colvin, V. L.; Alivisatos, A. P. J. Phys. Chem. 1994, 98, 4109 .

(25) Dabbousi, B. O.; Rodriguez-Viejo, J.; Mikulec, F. V.; Heine, J. R.; Mattoussi, H.; Ober, R.; Jensen, K. F.; Bawendi, M. G. J. Phys. Chem. B 1997, 101, 9463 .

(26) Cao, Y. W.; Banin, U. J. Am. Chem. Soc. 2000, 122, 9692.

(27) Liu, S.; Ma, Y.; Armes, S. P.; Perruchot, C.; Watts, J. F. Langmuir 2002, 18,7780 .

(28) Koktysh, D. S.; Liang, X.; Yun, B. G.; Pastoriza-Santos, I.; Matts, R. L.; Giersig, M.; Serra-Rodríguez, C.; Liz-Marzán, L. M.; Kotov, N. A. Adv. Funct. Mater. 2002, 12, 255.

(29) Liu, Y.-C.; Chuang, T. C. J. Phys. Chem. B 2003, 107, 9692.

(30) Boyen, H. G.; Kastle, G.; Weigl, F.; Koslowski, B.; Dietrich, C.; Ziemann, P.; Spatz, J. P.; Riethmuller, S.; Hartmann, C.; Moller, M.; Schmid, G.; garnier, M. G.; Oelhafen, P. Science 2002, 297, 1533.

(31) Yang, D.-Q.; Meunier, M.; Sacher, E. J. Appl. Surf. Sci. 2005, 173 134

(32) Piyakis, K. N.; Yang, D.-Q.; Sacher, E. Surf. Sci. 2003, 536, 139.

(33) Yang, D.-Q.; Gillet, J.-N.; Meunier, M.; Sacher, E. J. Appl. Phys. 2005, 97, 024303

(34) Tunc, I.; Suzer, S.; Correa-Duarte, M. A.; Liz-Marzan, L. M. J. Phys. Chem. B. 2005, 109, 7597.

(35) Ulgut, F.; Suzer, S. J. Phys. Chem. B 2003, 107, 1515.

(36) Karadas, F.; Ertas, G.; Suzer, S. J. Phys. Chem. B 2004, 108, 1515.

(37) Demirok, U. K.; Ertas, G.; Suzer, S. J. Phys. Chem. B 2004, 108 5179.

(38) Ertas, G.; Demirok, U. K.; Atalar, A.; Suzer, S. Appl. Phys. Lett. 2005, 86, 183110

(39) Fan, F. R. F.; Bard, A. J. Science 1997, 277, 1791.

(40) Chen, S.; Ingram, R. S.; Hostetler, M. J.; Pietron, J. J.; Murray, R. W.; Schaaff, T. G.; Khoury, J. T.; Alvarez, M. M.; Whetten, R. L. Science 1998, 280, 2098.

(41) Ohgi, T.; Fujita, D. Phys. Rev. B 2002, 66, 115410.

(42) Ohgi, T.; Sakotsuba, Y.; Ootuka, Y.; Fujita, D. Appl. Phys. Lett. 2004, 84, 604

(43) Ung, T.; Giersing, M.; Dunstan, D.; Mulvaney, P. Langmuir 1997, $13,1773$.

(44) Ung, T.; Liz-Marzan, L. M.; Mulvaney, P. J. Phys. Chem. B 1999, 103,6770 .

(45) Oldfield, G.; Ung, T.; Mulvaney, P. Adv. Mater. 2000, 12, 1519

(46) Hirakawa, T.; Kamat, P. V. J. Am. Chem. Soc. 2005, 127, 3928.

(47) Doron-Mor, I.; Hatzor, A.; Vaskevich, A.; van der Boom-Moav, T.; Shanzer, A.; Rubenstein, I.; Cohen, H. Nature 2000, 406, 382.

(48) Cohen, H. Appl. Phys. Lett. 2004, 85, 1271 